IRSH 62 (2017), pp. 479-480 doi: I0.1017/S0020859017000360

(C) 2017 Internationaal Instituut voor Sociale Geschiedenis

\title{
Globalising Migration History: A Discussion Dossier
}

\section{INTRODUCTION}

Globalising Migration History: The Eurasian Experience (I6th-2 Ist Centuries) (Leiden and Boston, 2014), edited by Jan and Leo Lucassen, was published in 20I4. The volume begins with the editors explaining their new definition and typology of cross-cultural migrations (CCMs), aimed at enabling systematic comparisons over time and space (see Figure I. on page 523). Their main contention is that the mainstream conceptualization of migration as long-distance moves over international borders resulting in final settlement captures only a tiny part of the phenomenon, especially before the rise of the nation state. Their definition of cross-cultural migrations privileges neither international migration, nor one-way moves. Instead, they define four different cultural boundaries that need not necessarily involve crossing state borders: moves from the countryside to cities, moves between different ecological and cultural zones (land to land), seasonal migration, and temporary labour migration by soldiers and sailors to different cultural zones. At the core of their typology is a claim that, as a result of people's interaction and confrontation with different cultural repertoires, social change takes place and, therefore, CCMs are pivotal in understanding larger social, economic, and cultural developments. These assumptions are illustrated by examples drawn from the European continent in the period I 500-2000.

The core of the volume comprises chapters by specialists on migration in various parts of Eurasia, especially Russia, China, Japan, India, and parts of Southeast Asia. The contributors to Globalising Migration History were asked to apply the cross-cultural migration rate (CCMR) approach, or at least the basic ideas underlying it, to those parts of Asia they know best (for the formula, see Figure 2. on page 528). One result of this exercise is that we now have consistent and comparable cross-cultural migration rates for Europe, Russia, China, and Japan, which can be used to illuminate larger debates on divergent patterns of economic growth and labour relations.

The aim of the present discussion dossier is to establish how convincing the CCMR method is, and to what extent the results do indeed produce new insights, not only in the field of migration studies, but also in that of global labour history in general. For that reason, various migration specialists (Patrick Manning, Leslie Page Moch, Lynn Hollen Lees, and Leo Douw) have been invited to reflect on the Lucassen and Lucassen volume. In their rejoinder, the editors of Globalising Migration History first briefly summarize the CCMR approach, and then discuss the implications of the 
commentaries for the following five issues: the CCMR definition and the concept of culture; the method and sources; gender; the Great Divergence debate, and, finally, the relevance for global labour history. Jan and Leo Lucassen also reflect on the main ideas and concerns expressed by these four discussants in relation to the same five themes.

Jan Lucassen and Leo Lucassen 